\author{
Review \\ Mosel, Ulrike \& Hovdhaugen, Even \\ Samoan reference grammar \\ Oslo: Scandinavian University Press, 1992, pp. xxii +819 \\ Reviewed by JEFFREY HEATH \\ University of Michigan
}

This is a 'reference' grammar rather than a read-through work in every sense enormous in size and detail, non-theoretical by design, privileging basic morphology and syntax over phonology, working semantics in where it elucidates basic grammatical patterns. Since it is based primarily on a diglossic 'high' variety used in a (by now) extensive body of written Samoan (including missionary Bibles), and to a lesser extent on direct study of the vernacular, the book resembles a corpus-based reference grammar of a major language rather than a fieldworker's description of a previously unknown language. The authors have imposed high standards of evidence on themselves, candidly admit uncertainties about the data on certain points, and do not shrink from correcting flawed empirical claims in earlier publications (including those of the first author).

The introduction (pp. 3-18) discusses the history of Samoan linguistics beginning with the early missionaries, the development of written Samoan, and the present diglossic situation. The brief chapter 2, "phonology and orthography" (pp. 19-47), describes a few unremarkable phonological contractions, indicates differences between high and low Samoan phonology, and makes short side-trips on loanword phonology and intonation. There follows an overview chapter on syntax ("the sentence: a preliminary view", pp. 49-65), which introduces basic terminology.

After these preliminaries we get the main substantive chapters: "Word classes" (69-164), "Morphology" (165-250), "Noun phrase" (251-327), "Verb phrase" (329-402), "Semi-verbal phrases" (403-11), "Basic verbal clauses" (413-51), "Non-basic verbal clauses" (453-97), "Nominal clauses and their negation" (499-521), "Semi-verbal clauses" (523-27), "Nominalised verbal clauses" (529-79), "Semi-nominalized verbal clauses" (581-84), "Complex sentences with embedded clauses" (585-650), "Complex sentences with depen- 
dent non-embedded clauses" (651-74), "Coordination" (675-91), "Case marking and grammatical relations" (693-774).

As can be seen from the chapter titles, the grammar is organized largely around phrase and clause types, each of which is defined, carefully analysed, and abundantly exemplified with sentences or slightly longer segments from Samoan literature. Statistics are generally absent, and discourse-sensitive analysis is not emphasized, but the few functional sections that crop up are useful (pp. 448-9 on the role of 'focus' in constituent order, pp. 474-6 on 'topic of discourse' and 'emphasis' in connection with fronting). The extras bringing up the rear are a useful word list (including all particles and bound elements) with page references, a topical index, and a ten-page bibliography. The table of contents is also a very helpful navigational guide, since it includes fine-grained subchapter headings - in general, the authors have bent over backwards to make the grammar user-friendly. In the remainder of the review I will comment on just a few points.

The morphology chapter does not shy away from giving exhaustive, multipage lists of derivatives involving unproductive or phomologically irregular affixes. It also identifies frozen formations of interest to historical linguists. There is an interesting discussion of the now somewhat archaic set of quantifying food classifiers.

In the chapter on word classes, the authors suggest somewhat tentatively that there may be no lexical distinction between (underived) noun and verb stems, i.e. that "... the categorisation of words into nouns and verbs is not given a priori in the lexicon. It is only their actual occurrence in a particular syntactic environment which gives them the status of a verb or a noun" ( $p$. 77). They point out that most underived nouns are attested functioning syntactically as verbs (i.e. in predicative function with verbal inflections), and vice versa. They acknowledge that 'do' is not (yet?) attested in nominal function, nor 'thing' in verbal function, but hint that such constructions might turn up in a larger corpus; one would have appreciated some informant judgments here. The noun/verb undifferentiation is apparently not applicable to derivatives: "Samoan has some affixes which derive nouns and verbs (i.e. words which are nearly exclusively used as nouns or verbs) ..." (p. 84), though "nearly" hedges the point. Elsewhere the authors disregard noun/verb undifferentiation, using the convenient terms 'noun' and 'verb' for lexical classes as well as syntactic functions, e.g. "Numerals ... are a subclass of verbs in Samoan" (p. 115).

The concluding chapter, "Case marking and grammatical relations", is a more "theoretical" chapter reconsidering data most of which have already been presented in the descriptive syntax sections. A good part of the chapter tries to apply the by now somewhat threadbare notion of 'syntactic pivot', showing the influence of R.M.W. Dixon and of Role and Reference Grammar; the authors conclude, not surprisingly, that the notion is basically inapplicable in Samoan.

One can pay no higher tribute to a reference grammar than to recommend it 


\section{JEFFREY HEATH}

equally to such diverse groups as typologists, historical linguists, and educated native speakers (and writers). Though pure theoreticians will occasionally wish for additional data (on the noun/verb question, for example), for most purposes this is a definitive one-stop source.

[Received 1/3/94]

Dept. of Linguistics

1076 Frieze Building

University of Michigan

Ann Arbor, Michigan 48109-1285

USA 